Available online at http://docs.lib.purdue.edu/jate

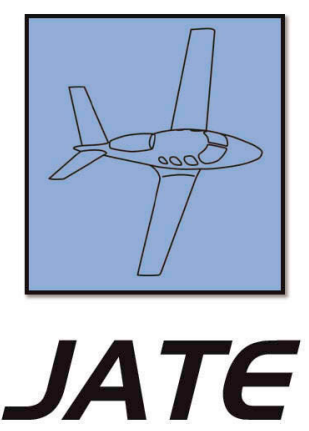

Journal of Aviation Technology and Engineering 5:2 (2016) 3-14

\title{
Pilot Source Study 2015: US Regional Airline Pilot Hiring Background Characteristic Changes Consequent to Public Law 111-216 and the FAA First Officer Qualifications Rule
}

\author{
Elizabeth Bjerke \\ University of North Dakota \\ Guy Smith \\ Embry-Riddle Aeronautical University_Daytona Beach \\ MaryJo Smith \\ Ypsilon Associates \\ Cody Christensen \\ South Dakota State University \\ Thomas Carney \\ Purdue University \\ Paul Craig \\ Middle Tennessee State University \\ Mary Niemczyk \\ Arizona State University
}


Abstract

This report is the first article in a series called Pilot Source Study 2015. Public Law (PL) 111-216, passed by the US Congress in 2010, and the subsequent FAA Regulation, Pilot Certification and Qualification Requirements for Air Carrier Operations Rule, abruptly changed the pilot hiring situation for US air carriers operating under 14 CFR Part 121. PL 111-216 became effective on August 1, 2013; thereafter, pilots were not eligible to be first officers in Part 121 air carriers unless they were certificated as Air Transport Pilots (ATP) with 1,500 hours of flight time, with some flight hour reductions for specified military and academic experiences. Recognizing that the rule had a notable impact on US regional airlines, the researchers visited 19 Part 121 regional airlines to extract data from their documents and records. De-identified background and corresponding performance data were recorded for 6,734 pilots hired after August 1, 2013. These data were analyzed in three articles, exploring the background characteristics of these pilots and determining to what extent there were differences in these background characteristics between post-law pilots (hired after August 1, 2013) and pre-law pilots (hired from 2005 to 2011). Besides the mandated increase in total flight hours and the requirement for an ATP certificate, the post-law pilots had less aviation-related academic experience, a lower proportion of flight instructors with more instructor experience, a larger proportion of military pilots, and a large range of flight experience suggesting career switching or returning to aviation. Among pilots with less experience, there was a significant reduction in multiengine time. This report is a preliminary article on the shift of pilot background characteristics as a result of the pilot certification and qualifications requirements mandated by Congress. Two future articles are being prepared. One article will analyze the success of post-law pilots in initial training for Part 121 operations, and another article will compare background and success factors between pilots hired before PL 111-216 and those hired after the law was passed.

Keywords: Public Law 111-216, Pilot Certification and Qualification Requirements for Air Carrier Operations, FOQ Rule, 14 CFR Part 121, ATP, R-ATP, pilot hiring, pilot training, first officer, transportation law, Airline Safety and Federal Aviation Administration Extension Act, airline pilot, new-hire pilot, flight hours, AABI

About the Authors

Elizabeth Bjerke currently serves as the Chair of the Department of Aviation at the University of North Dakota in Grand Forks, ND. After receiving her $\mathrm{PhD}$ in Educational Leadership, her research efforts have focused on student success in collegiate aviation programs, aviation assessment, and accreditation practices, as well as being a researcher on the 2010 and 2012 Pilot Source Studies.

Guy Smith is an associate professor of Aeronautical Science at Embry-Riddle Aeronautical University in Daytona Beach, FL. He is a 21 -year US Navy veteran where most of his career was on aircraft carriers flying the S-3A Viking. He earned a doctorate in Adult and Higher Education from Montana State University in 1994 and is best known for his research in facilitation teaching methods for adult learners and airline pilot training.

MaryJo Smith is the senior research scientist and CEO of Ypsilon Associates-independent consultants specializing in qualitative and quantitative research and statistical analysis. She earned her PhD in Educational Psychology with an emphasis in Evaluation, Statistics, and Research from the University of Minnesota in 1999. In her role as an evaluation consultant, she is the ATQP Data Manager for two airline consortiums in Europe.

Cody Christensen received a doctorate in Adult and Higher Education in 2013 from the University of South Dakota. He is an assistant professor and program coordinator of the aviation program at South Dakota State University in Brookings, SD. His current research involves student safety, financial literacy, and agricultural aviation. He holds an Airline Transport Pilot certificate and was an airline captain for a regional airline before transitioning into academia.

Thomas Carney is a professor of Aviation Technology at Purdue University in West Lafayette, IN. He holds an Airline Transport Pilot certificate with over 48 years of experience as a pilot. He holds MS and PhD degrees in Atmospheric Science. His primary research areas of interest include aviation meteorology, synoptic-scale dynamics and energetics, the use of aircraft for airborne research applications, and pilots' use of weather technology in the cockpit.

Paul Craig earned a doctor of education degree in 1998 and is a professor of Aerospace at Middle Tennessee State University in Murfreesboro, TN. He has been the Principal Investigator on four NASA research grants, including work with computerized flight decks, scenario based training, team dynamics, and decision making. He holds an Airline Transport Pilot certificate and is a Gold Seal Flight Instructor.

Mary Niemczyk is an associate professor and Chair of the Aviation programs at the Polytechnic School of Arizona State University in Mesa, AZ. She has earned an academic degree in accounting, an MBA-aviation, and $\mathrm{PhD}$ in Learning \& Instructional Technology. Her research interests center on improving instructional and learning strategies to enhance the performance of individuals in complex, ill-defined environments, such as aviation. 


\section{Introduction}

On August 1, 2010, President Obama signed the Airline Safety and Federal Aviation Administration Extension Act (Public Law 111-216). The new law changed the landscape in the United States regarding hiring and training of entry-level airline pilots. Previously, 14 CFR Part 121 air carriers could hire first officers who did not hold an Airline Transport Pilot (ATP) certificate and without having attained a specific minimum number of flight hours beyond the minimum total hours to meet the requirements for the Commercial Pilot certificate. The new law dramatically changed the requirements for entry-level air carrier pilots, as it required first officers to possess the ATP certificate and 1,500 flight hours as a minimum hiring requirement. The law had a three year phase-in period and, during that time, the FAA Administrator was charged with determining whether advanced credit could be awarded to pilots so they could be hired with fewer than 1,500 flight hours, while still meeting the requirement in the law that they possess an ATP certificate.

The FAA convened an Aviation Rulemaking Committee (ARC) (FAA, 2013), consisting of airline pilot stakeholders and aviation educators; its members were asked to make recommendations to the FAA Administrator concerning the issue of flight time credit. One of the organizations represented on the ARC was the Aviation Accreditation Board International (AABI) (AABI, 2015). AABI is an organization of aviation stakeholders (e.g., educators, practitioners, industry representatives, airlines, and manufacturers) that evaluates the quality of collegiate aviation programs seeking accreditation. In order to provide critical data to the ARC, AABI initiated research studies that became known as the Pilot Source Study of 2010 (Smith, Bjerke, NewMyer, Niemczyk, \& Hamilton, 2010) and the Pilot Source Study of 2012 (Smith et al., 2013). Information from those studies was important in providing factual data related to the potential effects of the Pilot Certification and Qualification Requirements for Air Carrier Operations Rule (FAA, 2012), hereafter referred to as the FOQ Rule. In the FOQ Rule, the FAA Administrator made the final decision to allow flight hour credit toward a Restricted ATP certificate (R-ATP) for military pilot training and for recognized collegiate aviation coursework.

The R-ATP is a new pilot certificate class that allows an individual to hold an ATP without meeting the Annex 1 flight time requirements of the International Civil Aviation Organization (ICAO, 2015) for a "full" ATP. The holder of the R-ATP cannot act as pilot-in-command in air carrier operations, but does meet the other requirements of Public Law (PL) 111-216 for first officers. The law went into full effect on August 1, 2013. For graduates to receive an R-ATP certificate with reduced flight hours, colleges and universities offering collegiate aviation degrees were required to submit specified documentation, including coursework and plans of study, to the FAA to verify that their graduates could meet the criteria. In response, the FAA granted a large number of colleges and universities the authority to certify flight time credit of their graduates, making it possible for their graduates to apply for an R-ATP certificate and to be a Part 121 first officer with as few as 1,000 flight hours.

During the summer of 2015, when the new law and authorizations had been in place for two years, the Pilot Source Study researchers were asked by the AABI leadership to reexamine the restructured background and qualifications of entry-level first officers and their subsequent performance in Part 121 air carrier training and operations (Roddey, 2015). To support this effort, researchers traveled across the United States from April to October, 2015, and visited 22 regional airlines (three Part 135 airlines and 19 Part 121 airlines). Extensive data were collected from airline records of over 7,000 pilots hired since the new law took effect on August 1, 2013. The resulting effort represents the largest and most detailed investigation of entry-level airline pilots that has been conducted to date. The research project seeks to describe the background and experience of current entry-level air carrier pilots; to measure how well they performed in training and operations after they were hired; and to quantify the impact that the new rule has had on airline pilot hiring, training, and success for Part 121 first officers. This research is designed to provide accurate source data to inform all stakeholders and to deliver empirical information to decision-makers: the US Congress, the FAA, Part 121 airlines, and aviation curriculum designers. The analyses of these data are divided into three stages:

1. This report: A preliminary article on the shift of pilot background characteristics as a result of the pilot certification and qualifications requirements mandated by Congress.

2. A second report: An examination of the success of post-law new-hire pilots in initial training and operations as first officers for Part 121 airlines.

3. A third report: An analysis of background and success factors between pilots hired before PL 111216 became effective and those hired afterward.

\section{Review of the Literature}

Over the last six years, many changes to pilot qualifications, training, and hiring have transformed the US regional airlines. Prior to PL 111-216 and the subsequent FOQ Rule, regional carriers were able to hire commercial pilots with less than 1,500 total hours (FAA, 2015). Airlines were able to set their own hiring criteria, as long as the applicant possessed a Commercial Pilot certificate. Pilots were hired based on specific standards that each company set as part of their hiring process. After September 11, 2001, and later in the economic downturn of 2007, airline hiring criteria were adaptable, based on economic conditions. Each airline established its own qualifications for interviewing and hiring. Since the signing 
of PL 111-216, all pilots hired by US carriers have been required to have an ATP certificate; this requirement substantially changed the background characteristics of the pilot population entering the Part 121 regional airlines.

The FOQ Rule stated that "all pilots" operating in a Part 121 airline must possess an ATP Certificate; "all pilots" includes both the captain and the first officer (Shane, 2015). The ATP requires pilots to be at least 23 years old and have 1,500 hours of total flight time (FAA, 2013). With the changes to the FOQ Rule, all Part 121 pilots must complete the Airline Transport Pilot Certification Training Program (ATP-CTP), have 50 hours of multiengine experience, and possess an aircraft type rating before serving as first officers (FAA, 2013; Shane, 2015).

The FOQ Rule gave the FAA discretion to permit applicants to obtain an ATP certificate with fewer than the minimum flight hours and at a younger age, if they have completed specific training as determined by the FAA (FAA, 2013). The FOQ Rule provided an avenue for alternatively trained first officers to fly as required crewmembers under Restricted Airline Transport Pilot (R-ATP) privileges at the age of 21 instead of 23 years old. The following specific training meets the requirements for the R-ATP certificate:

- graduates from an FAA-approved R-ATP bachelor's degree program must have 1,000 hours;

- graduates from an FAA-approved R-ATP associate's degree program must have 1,250 hours;

- US military pilots must have 750 hours (FAA, 2013).

Regional airlines, usually operating in partnerships with US mainline carriers, had benefited from having a pool of less-experienced, less-seasoned pilots to fly as first officers in their operations. In the past, regional carriers carried a minority of the passengers flying in the US; however, in 2015 regional airlines operated more than $50 \%$ of the nation's commercial flights (RAA, 2015). Regional airlines in this feeder environment typically operate turboprop aircraft and jet aircraft having a maximum of 108 seats. They primarily transport passengers from smaller spoke cities to mainline carrier hub airports. According to the Regional Airline Association (2015), regional airlines carried almost 160 million passengers annually, accounting for nearly $40 \%$ of all domestic passenger enplanements, whereas steadily increasing load factors indicate growing use of regional aircraft (Shane, 2015).

The regional airlines have served as a residency program for airline pilots in which the regional airlines are expected to maintain the same level of safety as that of the major air carriers. According to the US Government Accountability Office (2014), "Regional airlines generally tend to have newer pilots who accumulate flight time in smaller aircraft and use that experience as a stepping stone to the higher wages offered at mainline airlines." The regional airline pilot supply is critical to maintaining the transportation infrastructure in the US.
Prior to PL 111-216, the Pilot Source Study 2010 (Smith et al., 2010) collected data from six regional airlines. This study analyzed 2,156 records of pilots hired from 2005 to 2009 and found that more than half of those new-hire pilots had a baccalaureate degree with an aviation focus. Nearly half of the pilots hired in that timeframe obtained their flight training in a collegiate aviation setting, and $73.4 \%$ had their flight instructor certification. Over half of the pilots in Pilot Source Study 2010 had fewer than 1,000 hours of flight experience.

After much discussion with industry, collegiate aviation, and government organizations, the need to expand the data to more accurately assess regional airline hiring of pilots became increasingly clear. The 2012 Pilot Source Study (Smith et al., 2013) was commissioned to retrieve data from seven additional regional airlines. Focusing on the variables collected in the first study, the 2012 Pilot Source Study analyzed 4,024 new pilot records and found that pilot background characteristics were very similar to pilots in the 2010 Pilot Source Study.

The 2010 and 2012 Pilot Source Studies examined the records of pilots hired when regional airlines had the ability to be selective in hiring practices, and each airline had its own specific criteria and hourly requirements for pilots. The pool of pilots for regional airline hiring was larger because it included commercial pilots and ATPs (FAA, 2013).

After PL 111-216 was signed, only ATPs, graduates of FAA-approved R-ATP institutes of higher education, and military trained R-ATP pilots could be hired by Part 121 airlines. The FAA (2015) "authorizes institutions of higher education to certify graduates of specific aviation degree programs for a restricted privileges ATP certificate with reduced aeronautical experience."

Although some organizations opine that a pilot shortage does not exist, other reports and current practices say otherwise (ALPA, 2014; USGAO, 2014). ALPA represents over 52,000 pilots and is the largest pilot union in the world; ALPA (2014) denies there is a pilot shortage but instead states that low pilot pay contributes to otherwise qualified pilots not entering the US regional airline market. The USGAO (2014) report suggested that pilot supply outweighs pilot demand at this time, but did state that 11 of 12 airlines interviewed had difficulties filling first officer positions. For the 21 regional airlines included in this study, all were currently hiring first officers and some airlines were also hiring captains (Airline Pilot Central, 2015).

To entice pilots to consider an airline pilot career, many regional airlines are offering incentives to fill their first officer requirements from the smaller available pilot population. One regional airline is currently offering a $\$ 20,000$ per year retention bonus until the year 2018 and a guaranteed interview program with a mainline airline (Airline Pilot Central, 2015). Additional incentives include paid training, airline-sponsored ATP-CTP courses, signing bonuses, referral bonuses, rapid upgrades, and tuition 
reimbursements (Airline Pilot Central, 2015; Templeton, 2015). Many regional airlines have raised the starting salaries of new-hire pilots; however, the average starting salary of the five lowest paying regional airlines is $\$ 20,661$ and the effective average wage with incentives for the top five regional airlines is $\$ 36,200$ (ALPA, 2014; Templeton, 2015). The highest starting salaries for regional airline first officers are still below the median annual earnings for a bachelor-prepared full-time worker in the United States (US Department of Education, 2015).

Both the 2010 and 2012 Pilot Source Studies were completed before PL 111-216 was implemented. PL 111216 significantly changed pilot hiring for regional airlines. This study, a preliminary report of the Pilot Source Study 2015, aims to answer the following research questions:

1. What are the background characteristics of Part 121 regional airline pilots hired since the enactment of PL 111-216 (post-law pilots)?

2. How do the background characteristics of Part 121 regional airline pilots, hired prior to the enactment of PL 111-216 (pre-law pilots), compare to background characteristics of regional airline pilots hired after the enactment of PL 111-216 (post-law pilots)?

\section{Methodology}

The 2010 and 2012 Pilot Source Studies (hereafter referred to as the pre-law study) were motivated by a need for quantitative data to respond to the Advance Notice of Proposed Rulemaking (ANPRM) (FAA, 2010) and to the Notice of Proposed Rulemaking (NPRM) (FAA, 2012), respectively. The 2015 Pilot Source Study (hereafter referred to as post-law study) was initiated by the participants at the January 2015 Pilot Supply Summit (Roddey, 2015) who wanted to know the effect of PL 111-216 on pilot hiring and pilot training in US regional airlines.

Both studies required the Principal Investigator (PI) to contact the president or CEO of the regional airline to request permission to collect data at their airline. This request always included a Non-Disclosure Agreement (NDA) as an assurance that their data would be secure, that identifying information (name, employee number, age, gender, race, etc.) would be deleted from the data prior to data release by the airline, and that access to the data would be limited to those directly involved in the analysis. For the pre-law study, it was sometimes difficult to obtain this permission and access to the data, because some airlines were reluctant to release data and were distrustful of published results. For the post-law study, the PI and several team members briefed the Regional Airline Association (RAA) Board of Directors, the Regional Operations Council, and the Flight Training Committee at the May 11-14, 2015 RAA Annual Convention in Cleveland, Ohio (RAA, 2015c, May). Following those briefings, RAA
Table 1

Airlines in the pre-law study.

\begin{tabular}{ll}
\hline Phase 1 (2010 Pilot Source Study) & Phase 2 (2012 Pilot Source Study) \\
\hline Atlantic Southeast & Air Wisconsin \\
Cape Air & Atlantic Southeast \\
American Eagle & Chautauqua \\
Mesa & ExpressJet \\
Trans States & Republic \\
Horizon & Shuttle America \\
& SkyWest \\
\hline
\end{tabular}

members welcomed the Pilot Source Study team to collect data at their respective carriers.

The pre-law study was a convenience sampling of the regional airlines; data were collected from airlines that agreed to participate in the study during two time periods. Table 1 shows the airlines that participated in Phases 1 and 2 of the pre-law study. Data from all of these airlines are included in this report except for data from Cape Air, which operates under 14 CFR Part 135 ("Operating Requirements: Commuter," 2015a).

The post-law study was conceived as another convenience sampling of the same airlines that participated in the pre-law study. The objective was to collect background and training data for pilots hired by these airlines after PL 111216 went into effect-from August 1, 2013 to the date of data collection. It became clear during the 2015 RAA Convention that many more airlines were eager to participate. As a result, the post-law study became a population study; the 2015 Pilot Source Study included essentially all of the pilots hired by all of the major regional airlines in the United States during that period. Table 2 lists the 22 airlines that participated in the post-law study. Only data from the 19 Part 121 airlines are included in this preliminary report; data from Cape Air, RAVN Alaska (Hageland), and Great Lakes, each currently operating under Part 135, will be included in a subsequent report.

In both studies, after the CEO or president approved data collection at the airline, the PI contacted the VP/Director of Flight Operations or the VP/Director of Training to

Table 2

Airlines in the post-law study.

\begin{tabular}{ll}
\hline & 2015 Pilot Source Study \\
\hline Air Wisconsin & Mesa \\
Cape Air & Piedmont* \\
CommutAir* & PSA* \\
Compass* & RAVN Alaska (Corvus)* \\
Empire* & RAVN Alaska (Hageland)* \\
Endeavor* & Republic \\
Envoy & Seaborne* \\
ExpressJet & Shuttle America \\
GoJet* & Silver* \\
Great Lakes* & SkyWest \\
Horizon & Trans States \\
\hline
\end{tabular}

*These airlines were not included in the pre-law study. 
establish connections with data managers and to determine the data collection schedule. The data collection for the Pre-Law study was conducted by approximately 30 graduate students, who were supervised by the PI through phone calls, texts, and emails. The lack of direct oversight of the data collection process resulted in some data being invalid, requiring a second or even third visit. To preclude a repeat of this issue, the data collection for the post-law study was conducted by an on-site PI accompanied by a trained full-time Data Collection Manager and assisted on occasion by six other data collectors. The latter methodology yielded 7,081 records from 22 airlines, collected over a period of seven months.

The data collectors for each study used different data collection protocols. In the pre-law study the data collectors used a SurveyMonkey (2010) data collection instrument that purposely limited the type and format of data for ease of data collection. In the post-law study, the Data Collection Manager supervised background data collection and followed a protocol in which background data were gathered from resumes, applications, online applications ("AirlineApps," 2002), and employee files. Concurrently, the PI collected training data from training records, operational records, online sources, and reports. At the completion of the site visit, the two sets of data were combined and de-identified before being released by the airline, as established by the NDA. A copy of both the identified data and the de-identified data was retained by a representative at each airline.

The PI prepared the data for analysis, creating the derived variables (aviation degree and AABI-accredited flight). The PI combined all of the Part 121 datasets into a single spreadsheet for this report. This dataset was transmitted to the seven $\mathrm{PhD}$ researchers (several assisted by graduate students) for analysis. All researchers and graduate students on the data analysis team signed an NDA for the data analysis and reports. Through meetings, emails, and conference calls, the data analysis team coordinated their results. To maintain objectivity in both studies, a researcher who was not associated with an AABI-accredited flight program, provided an independent analysis of the data.

This report is the first article in a series called Pilot Source Study 2015. Not all of the data collected for the Pilot Source Study were included in this first report. The Pilot Source Study 2010/2012 and Pilot Source Study 2015 included data from Part 135 operators; these data were excluded from this report because the FOQ Rule pertains only to Part 121 operators (Operating Requirements: Domestic, 2015b). This report also does not include the training data, nor does it analyze the effect of the background data on training. These considerations will be addressed in future reports in the series called Pilot Source Study 2015.

\section{Results}

The combined dataset contains 12,806 pilot records from Part 121 airlines; of those, 6,072 were pre-law records of pilots hired prior to PL 111-216 and 6,734 were post-law records of pilots hired after the effective date of PL 111216-August 1, 2013. As previously noted, the pilots in the pre-law data were from 13 regional airlines; the pilots in the post-law data were from 19 regional airlines.

\section{Descriptive and Inferential Statistics: College Background}

For the pilots, three fields relating to their college background were collected: (a) type of college degree (associate, bachelor, none, or unknown), (b) name of the college or university, and (c) the name of the college degree. The variable, aviation degree, was derived from name of the college degree; an aviation degree was any college degree that related to the aviation or aerospace industry (e.g., flight, aviation management, aeronautical science, aerospace engineering and aviation maintenance). Many of the aviation degrees were flight degrees, but not all. The variable, AABIaccredited flight, was derived from the name of the college or university, the name of the college degree, and the list of AABI-accredited flight programs (AABI, 2015). In the dataset, 133 (1\%) of the pilots' college degree information was not available. Table 3 outlines the college background characteristics.

For degree type, a Chi-square test of significance compared degree type between the pre-law and post-law datasets. No statistically significant difference was found for degree type between the pre-law and post-law pilots hired $\left(\chi^{2}(2)=3.963, p=0.138\right)$.

For aviation degree, 2,180 (17\%) of the pilots had missing data. A Chi-square test of significance compared aviation degree between the pre-law and post-law datasets. A statistically significant difference was found for aviation degree between the pre-law and post-law pilots hired $\left(\chi^{2}(1)=231.94, p<0.001\right)$. The proportion and distribution for the aviation degree was significantly different. Two-thirds of the pre-law pilots had an aviation degree,

Table 3

College background.

\begin{tabular}{lccccc}
\hline & \multicolumn{2}{c}{ Pre-Law } & & \multicolumn{2}{c}{ Post-Law } \\
\cline { 2 - 3 } \cline { 5 - 6 } \cline { 5 - 6 } & Frequency & Percent & & Frequency & Percent \\
\hline Degree Type & & & & & \\
$\quad$ Associate & 596 & $10 \%$ & & 625 & $10 \%$ \\
Bachelor & 4,440 & $73 \%$ & & 4,762 & $72 \%$ \\
No Degree & 1,036 & $17 \%$ & & 1,214 & $18 \%$ \\
$\quad$ Total & 6,072 & $100 \%$ & & 6,601 & $100 \%$ \\
Aviation Degree & & & & & \\
$\quad$ No & 1,436 & $34 \%$ & & $\mathbf{3 , 1 8 3}$ & $\mathbf{4 9 \%}$ \\
Yes & $\mathbf{2 , 7 4 2}$ & $\mathbf{6 6 \%}$ & & 3,265 & $51 \%$ \\
$\quad$ Total & 4,178 & $100 \%$ & & 6,601 & $100 \%$ \\
AABI Flight & & & & \\
$\quad$ No & 2,829 & $68 \%$ & & $\mathbf{5 , 2 0 7}$ & $\mathbf{7 7 \%}$ \\
Yes & $\mathbf{1 , 3 4 9}$ & $\mathbf{3 2 \%}$ & & 1,527 & $23 \%$ \\
$\quad$ Total & 4,178 & $100 \%$ & & 6,734 & $100 \%$ \\
\hline
\end{tabular}

Note: bolded values are statistically significant. 
whereas only half of the post-law pilots had an aviation degree (Figure 1 and Table 3).

For AABI-accredited flight, only pilots who graduated from an AABI-accredited flight program (AABI, 2015) are included. A Chi-square test of significance compared AABI-accredited flight between the pre-law and post-law datasets. A statistically significant difference was found in AABI-accredited flight between the hired pre-law and postlaw pilots $\left(\chi^{2}(1)=122.73, p<0.001\right)$. Approximately one-third of the pre-law pilots graduated from AABIaccredited flight programs, and less than one-fourth of the post-law pilots graduated from AABI-accredited flight programs (Figure 1 and Table 3 ).

College grade point average (GPA) was not collected in the pre-law data; in the post-law data collection, $38 \%$ of the pilots provided their GPA in application documents. The overall recorded average GPA was 3.34; the median $(50 \%$ percentile) GPA was 3.4; the minimum GPA was 2.0; and the maximum GPA was 4.0. The GPA variable should be used cautiously because the GPAs collected were selfreported in applications or resumes; the applicants likely included their GPA only if they deemed its inclusion as beneficial for hiring. For the post-law pilots with a reported GPA, the grouped GPA variable (percentage of records in the group) has the following distribution: GPA 2.0-2.5 (4.5\%); GPA 2.51-3.0 (22\%); GPA 3.01-3.5 (37\%); and GPA 3.51-4.0 (36\%).

Age was not collected in either dataset since age could potentially identify a pilot; however, degree year (the year a pilot graduated from college) can be considered a proxy for approximate age. Degree year was not collected in the prelaw data; in the post-law data, $55 \%$ of the pilots' records contained degree year. Figure 2 describes degree year ranging from 1971 to 2015. Of the pilots reporting degree year, $41 \%$ graduated within the last five years and $69.5 \%$ graduated within the last fifteen years. Note that the data in Figure 2 are decadal for the 1970s through 2000s, then per year for 2010 through 2015 .

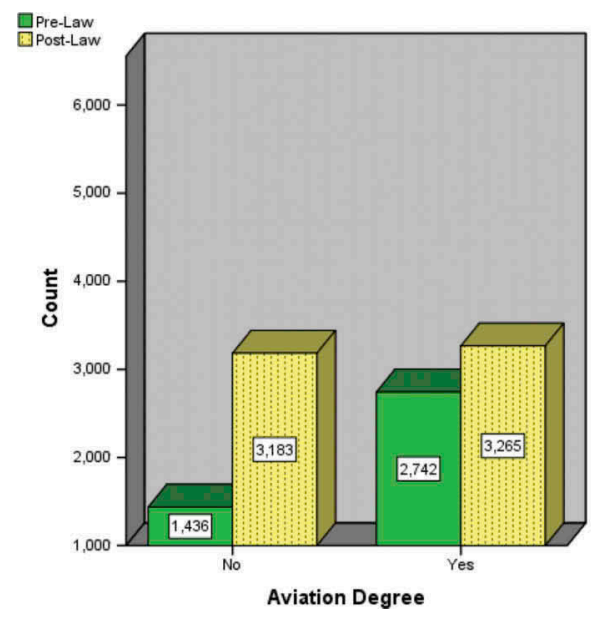

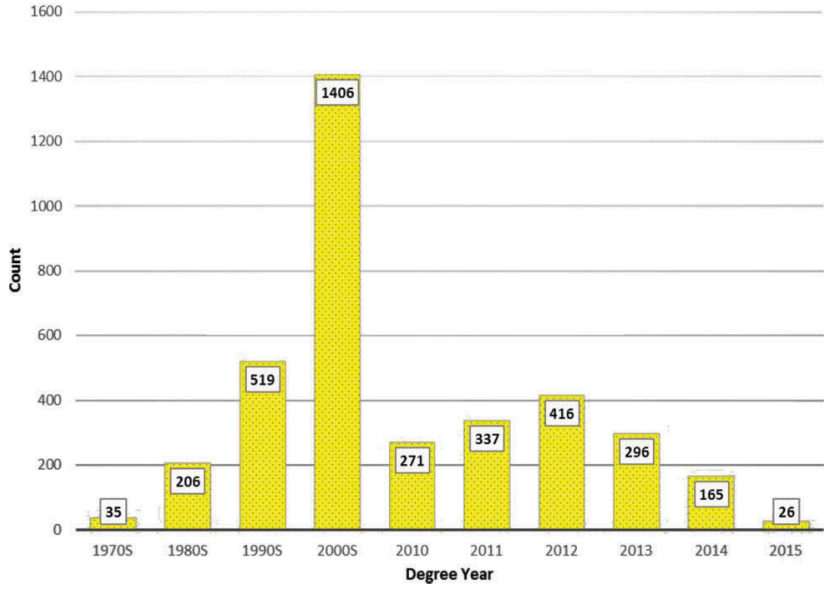

Figure 2. Degree year recorded in the post-law dataset.

\section{Descriptive and Inferential Statistics: Piloting Background}

The data collectors gathered data from application documents relating to their piloting background: pilot certificates, military background, previous experience, flight instructor experience, dual-given hours, cross-country hours, pilot in-command (PIC) hours, second in-command (SIC) hours, multiengine hours, turbine hours and total hours. The prelaw data contain only dual-given hours and total hours; the post-law data contain all the piloting background data that were available. Table 4 contains the pilot background categorical data.

Chi-square tests of significance compared pilot certification and military between the pre-law and post-law dataset. For the pre-law data, $11 \%$ of the hired pilots had an ATP certificate compared to the post-law data, for which $83 \%$ of the hired pilots had an ATP certificate. This change in pilots' certifications (required by the FOQ Rule) was understandably statistically significant $\left(\chi^{2}(3)=10,133\right.$, $p<0.001)$. For the pre-law data, only $3 \%$ of the pilots had a military pilot background; whereas, in the post-law data, $12 \%$ of the pilots had a military pilot background. The

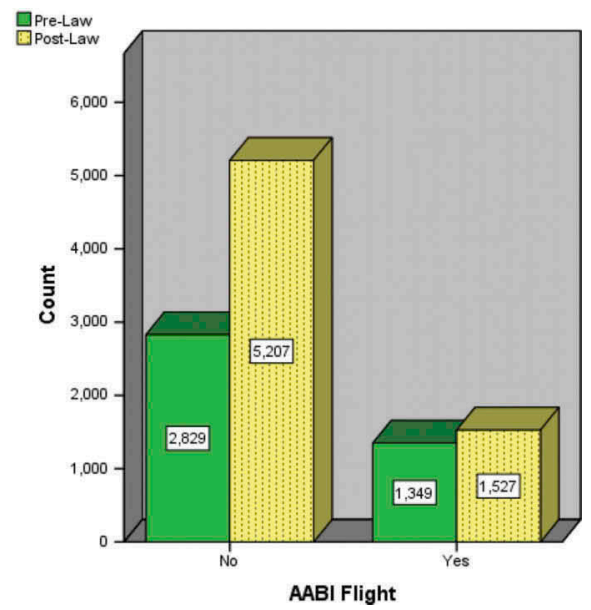

Figure 1. Comparison of aviation degree and AABI-accredited flight. 
Table 4

Piloting background categorical variables.

\begin{tabular}{|c|c|c|c|c|}
\hline & \multicolumn{2}{|c|}{ Pre-Law } & \multicolumn{2}{|c|}{ Post-Law } \\
\hline & Frequency & Percent & Frequency & Percent \\
\hline \multicolumn{5}{|l|}{ Certificates } \\
\hline Commercial & 5,060 & $89 \%$ & --- & --- \\
\hline Military-RATP & --- & --- & 141 & $2 \%$ \\
\hline Inst. Auth.-RATP & --- & --- & 1,036 & $15 \%$ \\
\hline ATP & 635 & $11 \%$ & $\mathbf{5 , 5 5 7}$ & $83 \%$ \\
\hline \multicolumn{5}{|l|}{ Military Pilot } \\
\hline No & 5,907 & $97 \%$ & 5,788 & $88 \%$ \\
\hline Yes & 165 & $3 \%$ & 778 & $12 \%$ \\
\hline \multicolumn{5}{|l|}{ Previous Experience } \\
\hline Flight Instructor & 2,901 & $53 \%$ & 2,405 & $46 \%$ \\
\hline Corporate & 826 & $15 \%$ & 1,072 & $20 \%$ \\
\hline Airline & 1,796 & $32 \%$ & 1,777 & $34 \%$ \\
\hline \multicolumn{5}{|l|}{ Instructor } \\
\hline No/Unknown & 1,087 & $18 \%$ & 1509 & $22 \%$ \\
\hline Yes & 4,985 & $82 \%$ & 5225 & $78 \%$ \\
\hline \multicolumn{5}{|c|}{ Dual-Given - Quartiles } \\
\hline $1-387 \mathrm{hrs}$ & 681 & $30 \%$ & 873 & $22 \%$ \\
\hline $388-728 \mathrm{hrs}$ & 749 & $33 \%$ & 804 & $21 \%$ \\
\hline $729-1,110 \mathrm{hrs}$ & 533 & $23 \%$ & 1,019 & $26 \%$ \\
\hline $1,111-8,833 \mathrm{hrs}$ & 317 & $14 \%$ & 1,235 & $31 \%$ \\
\hline \multicolumn{5}{|c|}{ Dual-Given at 200 hours } \\
\hline$\leq 200 \mathrm{hrs}$ & 324 & $14 \%$ & 449 & $11 \%$ \\
\hline$>200 \mathrm{hrs}$ & 1,956 & $86 \%$ & 3,482 & $89 \%$ \\
\hline \multicolumn{5}{|c|}{ Total Hours - Quartiles } \\
\hline $178-1,112 \mathrm{hrs}$ & 2,662 & $45 \%$ & 490 & $7 \%$ \\
\hline $1,113-1,557 \mathrm{hrs}$ & 1,363 & $23 \%$ & 1,789 & $27 \%$ \\
\hline $1,558-2,575 \mathrm{hrs}$ & 1,202 & $20 \%$ & 1,947 & $29 \%$ \\
\hline $2,576-52,350 \mathrm{hrs}$ & 712 & $12 \%$ & 2,436 & $37 \%$ \\
\hline \multicolumn{5}{|c|}{ Total Hours - Regulatory } \\
\hline $178-500 \mathrm{hrs}$ & 490 & $8 \%$ & --- & $0 \%$ \\
\hline $501-1,000 \mathrm{hrs}$ & 1,484 & $25 \%$ & 292 & $5 \%$ \\
\hline $1,001-1,500 \mathrm{hrs}$ & 1,897 & $32 \%$ & 1,489 & $22 \%$ \\
\hline $1,501-3,000 \mathrm{hrs}$ & 1,549 & $26 \%$ & 2,802 & $42 \%$ \\
\hline $3,001-52,350 \mathrm{hrs}$ & 519 & $9 \%$ & 2,079 & $31 \%$ \\
\hline
\end{tabular}

Note: bolded values are statistically significant.

change in the proportion of military pilots hired by the regional airlines was statistically significant $\left(\chi^{2}(3)=381\right.$, $p<0.001)$. See Figure 3 and Table 4.

For previous experience, a Chi-square test of significance compared previous experience (flight instructor, corporate, or airline) between the pre-law and post-law dataset. A statistically significant difference existed $\left(\chi^{2}(2)=\right.$ $71.68, p<0.001)$. The proportion of flight instructors in the pre-law data was significantly higher than in the post-law data, and the proportion of corporate pilots in the post-law data was significantly higher than in the pre-law data. This shift in pilots' background was also found in the flight instructor variable. A Chi-square test of significance compared flight instructor between the pre-law and postlaw datasets. In the post-law data, $78 \%$ of the pilots were flight instructors compared to $82 \%$ of the pilots in the prelaw data. This change in the proportions for the flight instructor variable was statistically significant $\left(\chi^{2}(1)=\right.$ 40.13, $p<0.001$ ). See Figure 4 and Table 4 .
Many of the post-law pilots apparently gained the additional flight hours required by the FOQ legislation by flight instructing. Three variables describe flight instruction hours: dual-given (Table 5), dual-given categorized by quartiles (Table 4), and dual-given categorized at 200 hours (Table 4). An analysis of variance (ANOVA) (assuming unequal variances) tested for differences in dual-given hours between the pre-law and post-law pilots. The dual-given hours were significantly higher for the post-law pilots compared to the pre-law pilots $(F(1,6,209)=205, p<0.001)$.

Chi-square tests of significance compared both of the categorical dual-given variables between the pre-law and post-law dataset. Both variables were statistically significant. For dual-given by quartiles, the pre-law pilot group has significantly more pilots in the low (1-387 hour) quartile and in the medium (388-728 hour) quartile compared to the post-law pilots who had significantly more pilots in the very high $(1,111-8,833$ hour) quartile $\left(\chi^{2}(3)=303, p<0.001\right)$. For the dual-given at 200 hours, the pre-law pilots had significantly more pilots with low (less than or equal to 200) dual-given hours $\left(\chi^{2}(1)=10\right.$, $p=0.001)$. See Figure 5 .

Total hours at the date of hire were collected; data were not available for 205 pilots. Table 5 displays the descriptive statistics for total hours. An ANOVA (assuming unequal variances) tested for differences in total hours between the prelaw and post-law pilots. The differences between pre-law and post-law total hours are statistically significant $(F(1,12,599)=$ $1,196, p<0.001)$. Figure 6 displays the box plot and area plot of total hours. The box plot of pre-law and post-law pilots had many records that are considered to be outliers (the starred values above the upper horizontal line in the box plot); the outliers begin for the pre-law pilots at $\sim 3,200$ hours and for the post-law pilots at $\sim 6,500$ hours. The area plot shows the skewness of the data-fewer observations at the top (skewness $=4.161$ ). Additionally, the distribution is bimodal (1,000 and 1,500 hours) and leptokurtic (kurtosis = 30.536).

To minimize the influence of the outliers, two categorical variables were created: total hours by quartile (mathematical) and total hours regulatory (based on the 1500-hour rule) (FAA, 2010). Figure 7 is a graphical description of these categorical variables.

Chi-square tests of significance compared both of the total hours variables between the pre-law and post-law dataset. Both of these categorical variables were statistically significant (see Table 4). For total hours by quartile, the pre-law pilots had significantly more pilots in the low (178-1,112 hours) quartile, whereas the post-law pilots had significantly more pilots in the medium (1,113-1,557 hours) and high (2,576-52,350 hours) quartiles $\left(\chi^{2}(3)=\right.$ $2,642, p<0.001)$. For total hours regulatory, the pre-law pilots had significantly more pilots in the very low (178500 hours), low (501-1,000 hours), and medium (1,0011,500 hours) groups, whereas the post-law pilots had significantly more pilots in the high (1,501-3,000 hours) 

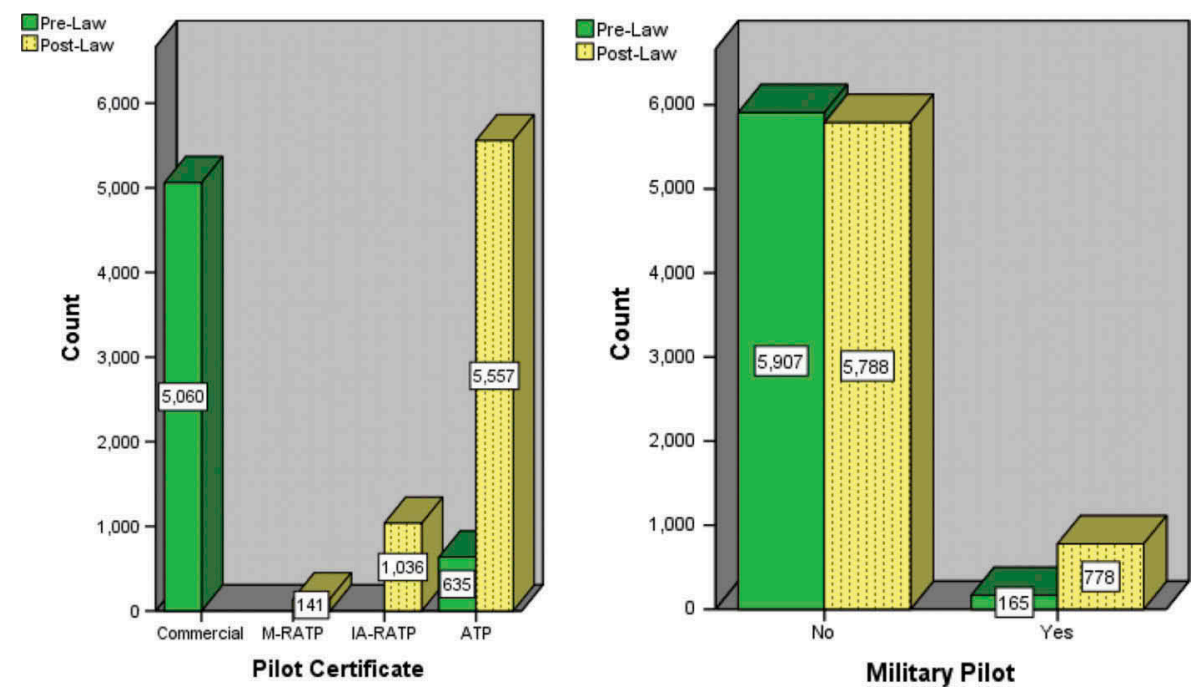

Figure 3. Pilot certificate and military pilot background.
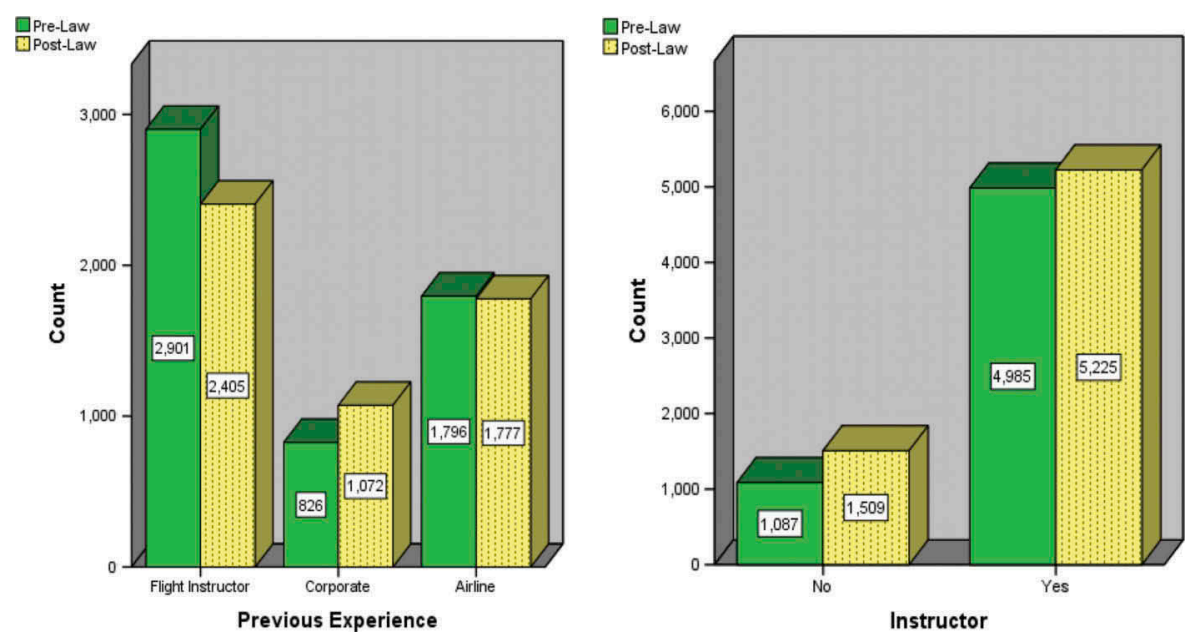

Figure 4. Previous experience and flight instructor.

Table 5

Dual-given and total hours compared by pre-and post-law groups.

\begin{tabular}{lrrrrrr}
\hline & \multicolumn{2}{c}{ Dual-Given } & & \multicolumn{2}{c}{ Total Hours } \\
\cline { 2 - 3 } \cline { 6 - 6 } \cline { 5 - 6 } & Pre-Law & Post-Law & & Pre-Law & Post-Law \\
\hline Number of Records & 2,280 & 3,931 & & 5,939 & 6,662 \\
Mean & 689 & 940 & & 1,597 & 3,071 \\
Minimum & 2 & 1 & & 178 & 750 \\
25th Percentile & 328 & 445 & & 850 & 1,500 \\
Median/50th & 616 & 840 & & 1,198 & 1,924 \\
$\quad$ Percentile & 877 & 1,213 & & 1,800 & 3,546 \\
75th Percentile & 5,000 & 8,833 & & 22,000 & 52,350 \\
Maximum & & & & &
\end{tabular}

and very high $(3,001-52,350$ hours $)$ groups $\left(\chi^{2}(4)=2,604\right.$, $p<0.001)$.

The post-law data contained six variables that were not in the pre-law data: total instrument hours, cross country hours, pilot in-command (PIC) hours, second in-command (SIC) hours, multiengine hours, and turbine hours. The number of records for each variable varied. The descriptive statistics are found in Table 6 . The 75 th percentile for these six variables indicates that the post-law pilots were very experienced.

Three of these variables are especially important to the regional airlines (instrument hours, cross country hours, and multiengine hours). Using the median (50th percentile) of these hours, three post-law hours variables were categorized with the median hours as center point. Figures 8 through 10 display these variables.

Further analysis was conducted between multiengine hours and type of ATP certificate (military R-ATP, institutional authority R-ATP, or traditional ATP). A Chi-square test of significance compared multiengine hours between the pre-law and post-law dataset. Institutional authority R-ATP applicants have significantly fewer multiengine hours than the other two groups $\left(\chi^{2}(6)=1,186.075, p<0.001\right)$.

\section{Discussion}

Since the enactment of PL 111-216, numerous market changes have occurred in the airline industry that have had 

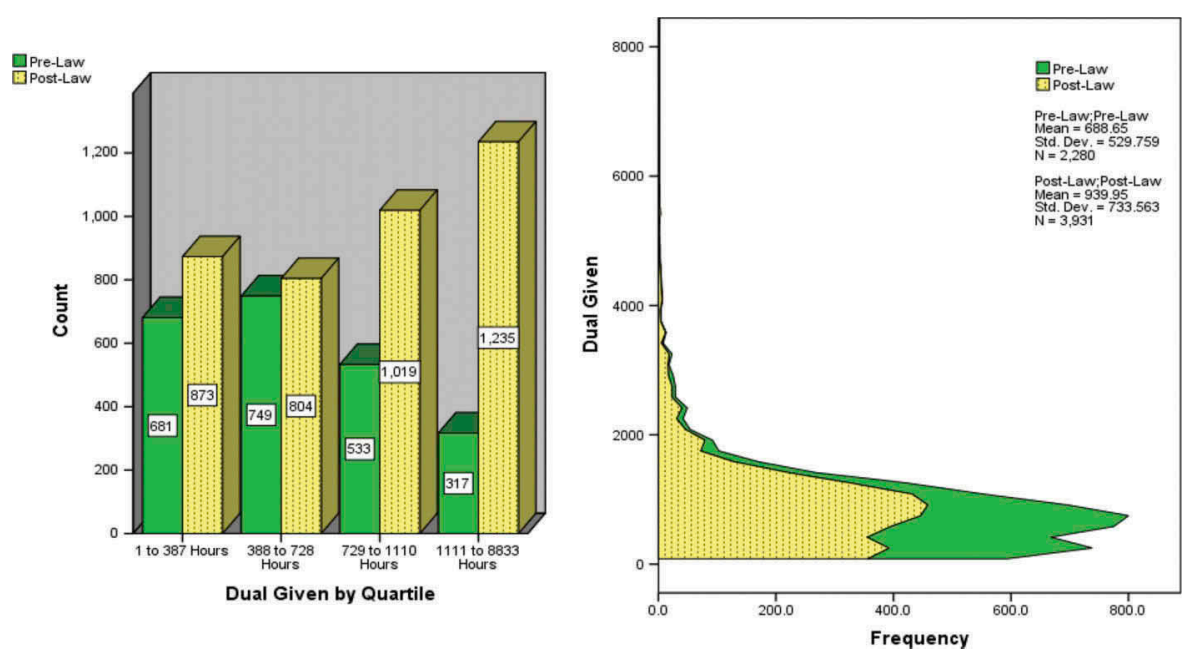

Figure 5. Dual-given hours (by quartile and cumulative frequency distribution).
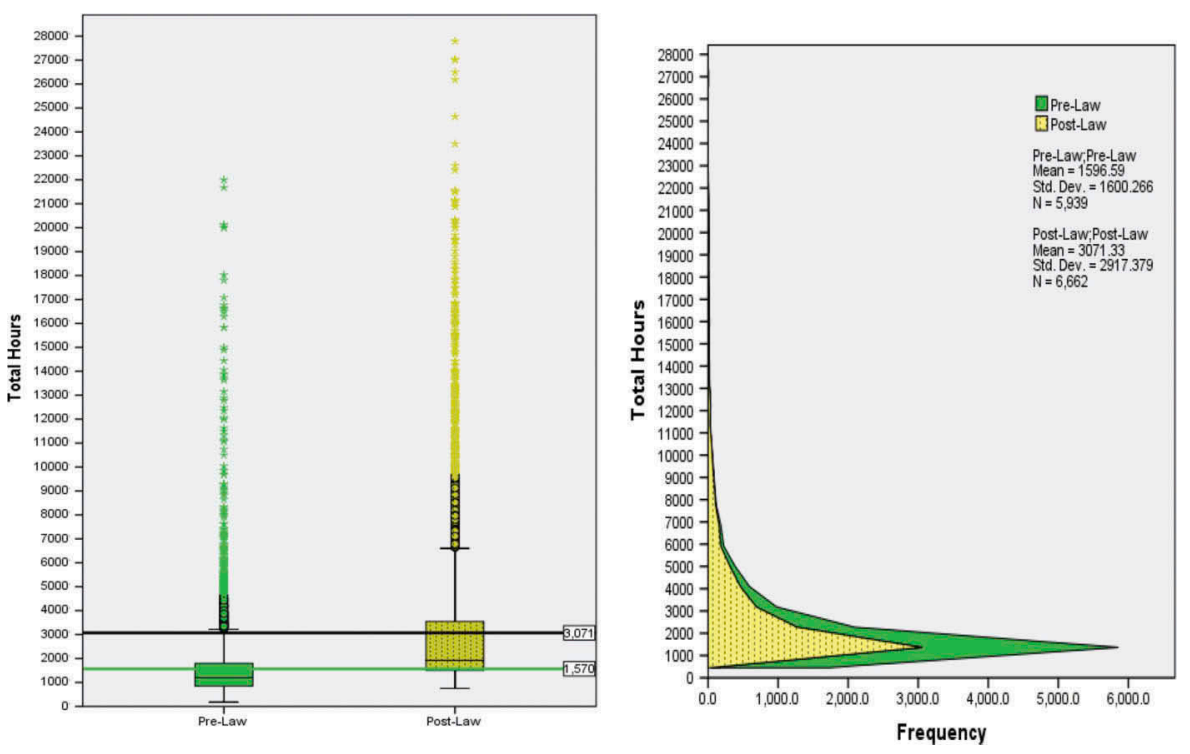

Figure 6. Box-plot of total hours (left) and area plot of total hours (right).
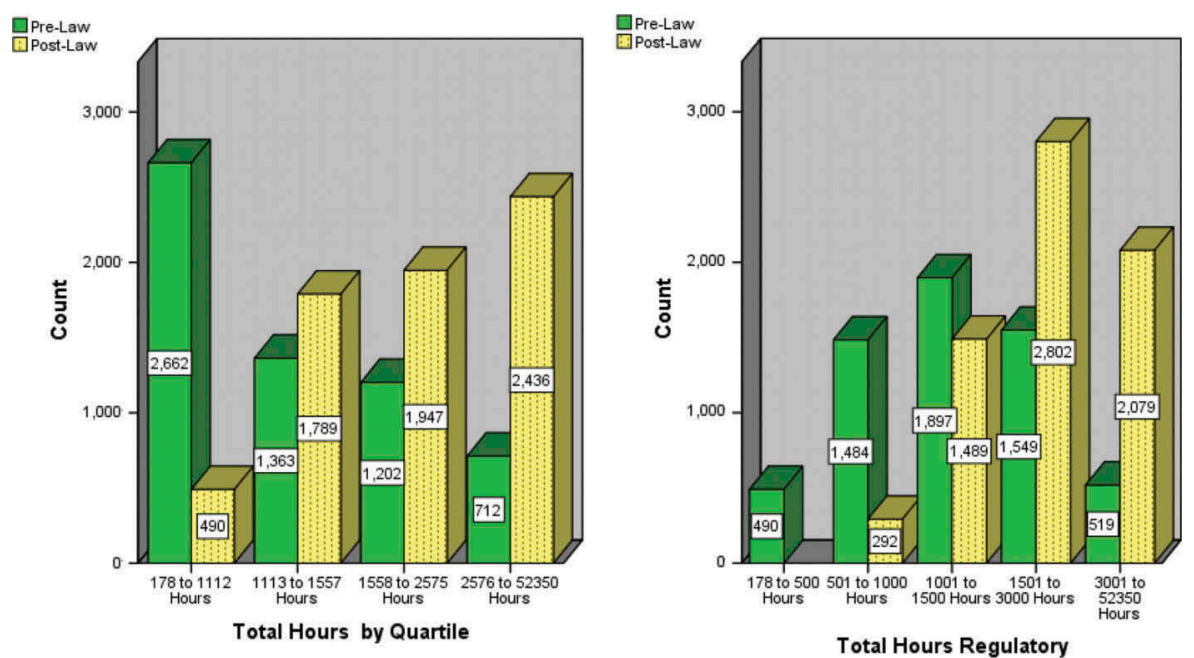

Figure 7. Total hours by quartile and total hours regulatory. 
Table 6

Piloting background hours from post-law pilots.

\begin{tabular}{lrrrrrr}
\hline & $\begin{array}{c}\text { Total } \\
\text { Instr. }\end{array}$ & \multicolumn{1}{c}{ XC } & \multicolumn{1}{c}{ PIC } & SIC & $\begin{array}{r}\text { Multi- } \\
\text { engine }\end{array}$ & Turbine \\
\hline \# of Records & 4,797 & 4,744 & 5,636 & 2,526 & 6,417 & 3,834 \\
Mean & 358 & 1,914 & 1,841 & 1,395 & 1,639 & 2,087 \\
Minimum & 51 & 11 & 101 & 1 & 1 & 1 \\
25th Percentile & 105 & 515 & 717 & 306 & 135 & 328 \\
50th Percentile & 174 & 923 & 1,319 & 849 & 559 & 1,140 \\
75th Percentile & 373 & 2,141 & 2,014 & 1,876 & 1,972 & 2,843 \\
Maximum & 17,500 & 25,500 & 38,600 & 12,976 & 49,850 & 38,800 \\
\hline
\end{tabular}

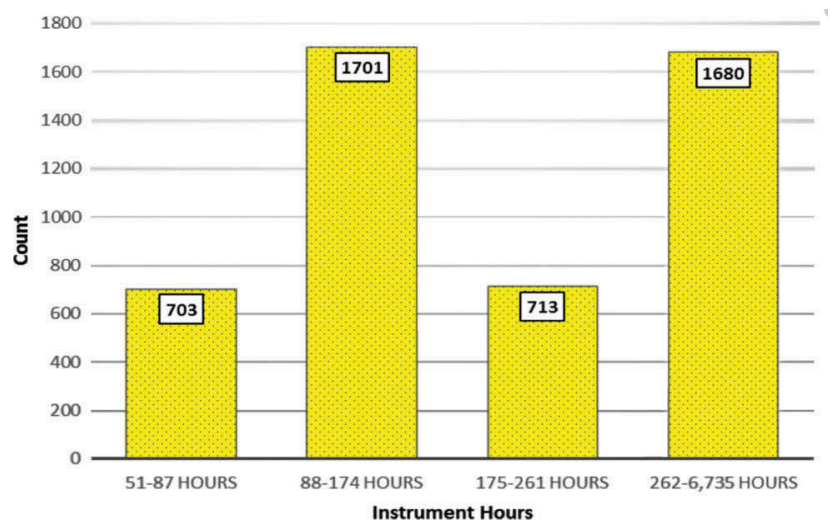

Figure 8. Instrument hours categorized by median hours.

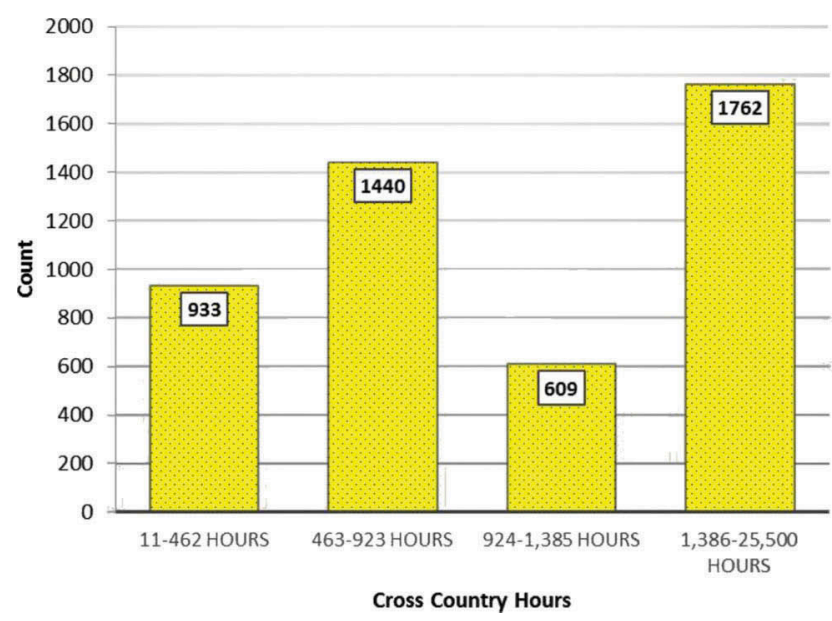

Figure 9. Cross country hours categorized by median hours.

an impact on the supply and demand of certificated pilots. Demand for air travel has risen (Airlines for America, 2015; IATA, 2015), and airline pilots at the major airlines are retiring in record numbers (Carey \& Nicas, 2014), prompting US major airlines to hire pilots in record numbers for the first time since 2001. The impact of these market changes on the regional airline pilot applicant pool requires further examination and discussion.

Although this study found no significant difference in the level of education attained by regional pilot applicants in the pre-law and post-law datasets, a significant difference was found in aviation-related degrees and AABI-accredited flight

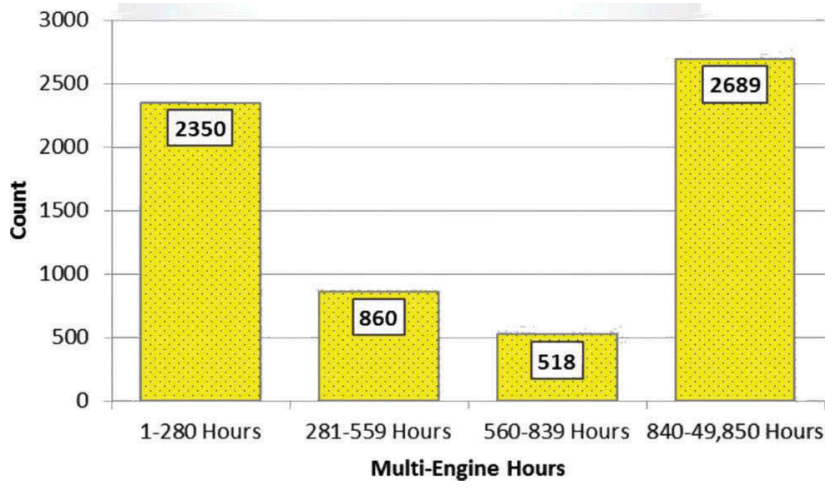

Figure 10. Multiengine hours categorized by median hours.

degrees. In the pre-law dataset, $66 \%$ of pilots had an aviationrelated degree, whereas in the post-law dataset only $49 \%$ of the pilots had an aviation-related degree. Similarly, in the pre-law dataset, $32 \%$ of pilots had an AABI-accredited flight degree, whereas only $23 \%$ of the pilots in the post-law dataset had an AABI-accredited flight degree. Further analysis of the Pilot Source Study data should show how this change in educational background characteristics affected the success rate of the post-law pilots.

The degree year variable provided an interesting finding. In a traditional career progression, an aspiring airline pilot graduated from a collegiate aviation program, built time by flight instructing for several years, and then was hired by a regional airline. In the post-law dataset, 59\% of the regional pilot applicants graduated more than five years ago, with $21 \%$ graduating more than 15 years ago. This finding indicates that a large percentage of applicants are either mid-career switching or coming back to aviation after an extended period away from flying as an occupation. One explanation for this finding is that the major airlines are finally in a hiring mode after nearly 15 years of stagnant activity; these pilots may be applying to the regional airlines, anticipating a move to the major airlines in the not-too-distant future.

The impact of major airline hiring also may explain the increase in the number of military-trained pilots who are applying to fly at the regional airline level. In the pre-law dataset, only $3 \%$ of regional pilot applicants came from the military, whereas in the post-law dataset, there was a significant increase to $12 \%$ military pilots. Further analysis of the Pilot Source Study data may provide an insight to this change in pilot demographic.

As expected, pilots in the post-law dataset had significantly more total flight hours than pilots in the pre-law dataset. The legislative and regulatory changes took away the ability for the regional airline hiring market to set the desired hiring minimums. The market demand for pilots at the regional level has also seen a decrease in desired aeronautical experience in one area in particular, multiengine hours. Prior to the enactment of PL 111-216, airlines were able to set their preferred hiring minimums, as long as the applicants held a Commercial Pilot certificate. Depending on the applicant's educational 
background, the airline might require a certain number of total flight hours, often including a certain number of multiengine hours. Prior to the legislative change, a typical regional airline might have required $600-1,000$ hours of total time with 200-400 hours of multiengine time. Since the regulatory changes to the ATP requirement and the creation of the R-ATP, these flight time requirements have changed. The minimum total flight time requirements are 750, 1,000, or 1,250 hours for the R-ATP or 1,500 hours for the traditional ATP. Though the FOQ rule extended overall flight time, it reduced minimum multiengine time to 50 hours. In some cases, regional airlines hire pilot applicants with 25 multiengine hours, as the new-hire pilots obtain at least 25 multiengine hours in a full-motion simulator; counting toward the FAA-required 50 multiengine hours (GoJet Airlines, 2015).

The impact of lowering the required multiengine hours from 200 to 25 hours has had an immediate impact on many flight schools around the country who are training the next generation of aviation professionals. Historically, aspiring pilots pursued their multiengine instructor rating as a way to build the multiengine hours desired by the airlines. Now, the need to build multiengine hours beyond the hours required during the initial multiengine commercial rating has been eliminated. As a result, flight schools around the nation are struggling to find qualified multiengine instructors. This unexpected consequence is negatively influencing the future supply of multiengine-rated pilots.

This report is the first article in a series called Pilot Source Study 2015. This report focused solely on the background characteristics of pilots. It compared these background characteristics of pilots hired prior to the enactment of PL 111-216 and those hired after the effective date of the law, August 1, 2013. This report showed significant differences in these background characteristics between the pre-law and post-law pilot groups. Some differences were direct results of Public Law 111-216 and the subsequent FOQ Rule; other differences may have been unintended consequences. The next report of the Pilot Source Study 2015 will determine to what extent these changes in background characteristics impacted the success of these pilots in their initial training at the regional airlines.

\section{References}

Air Line Pilots Association, International (ALPA). (2014). ALPA refutes myth of US pilot shortage [Press Release]. Retrieved from http://www. alpa.org/news-and-events/news-room/2014-02-04-Myth-Pilot-Shortage

Airline Pilot Central. (2015). Airlines currently hiring. Retrieved from http://www.airlinepilotcentral.com/airlines/currently_hiring

Airline Safety and Federal Aviation Administration Extension Act of 2010. Public Law. No. 111-216, 124 Stat. 2348. (2010).

AirlineApps. (2002). Online application service for the airlines. Retrieved from http://www.airlineapps.com/default.asp

Airlines for America. (2015). A4A projects summer air travel to reach alltime high. Retrieved from http://airlines.org/news/summer-air-travelto-reach-all-time-high/

Aviation Accreditation Board International (AABI). (2015). Accredited programs. Retrieved from http://www.aabi.aero/programs.html
Cary, S. \& Nicas, J. (2014, February 3). Airline-pilot shortage arrives ahead of schedule. The Wall Street Journal. Retrieved from http://www.wsj.com/ articles/SB10001424052702304851104579361320202756500

Federal Aviation Administration (FAA). (2010, February 8). New pilot certification requirements for air carrier operations (ANPRM, Docket No. FAA-2010-0100; Notice No. 10-02). Washington, DC: Department of Transportation.

Federal Aviation Administration (FAA). (2012, February 29). Pilot certification and qualification requirements for air carrier operations (NPRM, Docket No. FAA-2010-0100; Notice No. 12-01). Washington, DC: Department of Transportation.

Federal Aviation Administration (FAA). (2013, July 2). Airline transport pilot certification training program (AC No: 61-138). Washington, DC. Retrieved from http://www.faa.gov/documentLibrary/media/ Advisory_Circular/AC_61-138.pdf

Federal Aviation Administration (FAA). (2015). Pilot training: ATP certificate. Retrieved from https://www.faa.gov/pilots/training/atp/

GoJet Airlines. (2015). Pilots: Signing bonus, fast upgrade—at GoJet, you can have both. Retrieved from http://www.gojetairlines.com/careers/ Pages/Pilots.aspx

International Air Transport Association (IATA). (2015). Strong demand for air travel rises in 2014. Retrieved from http://www.iata.org/ pressroom/pr/Pages/2015-02-05-01.aspx

International Civil Aviation Organization (ICAO). (2015). The convention on international civil aviation: Annexes 1 to 18.

Operating Requirements: Commuter and On Demand Operations and Rules Governing Persons on Board Such Aircraft Rule, 14 C.F.R. § 135 (2015a).

Operating Requirements: Domestic, Flag, and Supplemental Operations Rule, 14 C.F.R. § 121 (2015b).

Regional Airline Association (RAA). (2015a). 2015 Annual report: 40th Anniversary. Retrieved from http://www.raa.org/?page=Industry_ Statistics

Regional Airline Association (RAA). (2015b). Mission statement. Retrieved from http://www.raa.org/?page=Mission_Statement

Regional Airline Association (RAA). (2015c, May 11-14). RAA 40th annual convention: schedule of events. Retrieved from http://c.ymcdn. com/sites/www.raa.org/resource/resmgr/2015AC/RAA2015SOE.pdf

Roddey, J. (2015, January 12). Airline industry leaders gather at EmbryRiddle to discuss pilot shortage. PRNewswire-US Newswire, p. 1.

Shane, N. R. (2015). The impact of the first officer qualification ruling: Pilot performance in initial training. Journal of Aviation Technology and Engineering, 5(1). Retrieved from: http://dx.doi.org/10.7771/21596670.1118

Smith, G. M., Bjerke, E., NewMyer, D. A., Niemczyk, M., \& Hamilton, R. A. (2010). Pilot source study: An analysis of pilot backgrounds and subsequent success in US regional airline training programs. International Journal of Applied Aviation Studies, 10(1).

Smith, G. M., Herchko, D., Bjerke, E., Niemczyk, M., Nullmeyer, R., Paasch, J., \& NewMyer, D. A. (2013). The 2012 pilot source study (phase III): Response to the pilot certification and qualification requirements for air carrier operations. Journal of Aviation Technology and Engineering 2(2), 13-23.

SurveyMonkey [Web-based surveys]. (2010). Menlo Park, CA:

Templeton, P. (2015). Regional airlines are offering signing and retention bonuses to pilots. ATP Flight School. Retrieved from: http://pilotjobs. atpflightschool.com/2015/02/09/regional-airlines-are-offering-signingand-retention-bonuses-to-pilots/

US Department of Education, National Center for Education Statistics. (2015). Annual earnings of young adults. The condition of education 2015 (NCES 2015-144). Retrieved from: https://nces.ed.gov/programs/ coe/indicator_cba.asp

US Government Accountability Office (USGAO). (2014). Aviation workforce: Current and future availability of airline pilots. Retrieved from http://www.gao.gov/products/GAO-14-232 